\title{
Comparative Trial between Neonatal Intensive Care Incubator, Neonatal Laminar Flow Unit and Radiant Warmer
}

\author{
Perez JMR ${ }^{1 *}$, Perez FR $^{2}$, Golombek $S^{3}$ and Sola $\mathbf{A}^{\mathbf{4}}$ \\ ${ }^{1}$ Head of the International Neonatal Neurodevelopment Center (CINN), Brazil \\ ${ }^{2}$ Pediatric resident of the Secretaria Municipal de Saúde da cidade de São Paulo, Brazil \\ ${ }^{3}$ Maria Fareri Children's Hospital, USA \\ ${ }^{4}$ New York Medical College, USA
}

*Corresponding author: José Maria rodriguez Perez, Head of the International Neonatal Neurodevelopment Center, Brazil

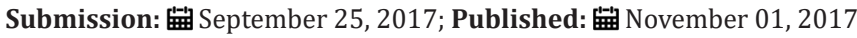
Abstract with an objective punctuation incubators, 28 newborns used laminar flow unit and 14 newborns used radiant warmer. We have evaluated six items:
a. The speed of recovery of body temperature of newborns in use of the three equipment
b. Bacteria contamination level in the microenvironment inside the three equipment
c. Humidity level in the microenvironment inside of the three equipment
d. Easy access to the care of the newborn in use of the three equipment
e. Level noise of the microenvironment in the three equipment
f. Spent time for terminal disinfection of the three devices

Aim: This was a trial to compare three equipment, intensive care incubator, laminar flow unit and radiant warmer; to care newborns using six items

Methods: We enrolled infants 71 born at up to 38 weeks of gestation until 42 weeks, which were distributed 29 newborns used intensive care

According to the result obtained we assign the value 0 to worse result, 1 to intermediate result and 2 to better result found in the evaluation of the three equipment

Results: In total punctuation we had 3 points to intensive care incubators, 8 points to radiant warmer and 9 points to laminar flow unit.

Conclusion: In this analysis, the equipment with the best results to care newborns was the neonatal laminar flow unit and the worst result was neonatal intensive care incubator.

\section{Introduction}

The use of incubators to manage ill newborns dates more than one hundred years of history [1] however until now days there are limitations to it use, as poor isolation [2], very difficult to access the newborn and high noise [3]. The use of radiant warmer emerges in the 1970s, in attempt to improve the control of the microenvironment $[1,2,4]$. The neonatal laminar flow unit was created and developed in Brazil since 2004, and its concepts and its use to supply hypothermia therapy in newborns have been published [5-7].

\section{Objective}

To compare, we have used an objective numeric score, between neonatal intensive care incubator, neonatal laminar flow unit and radiant warmer. We have compared the speed of recovery of body temperature of newborns, level bacteria contamination, level humidity microenvironment, easy access to manage newborn, level noise and finally the spent time for terminal disinfection of the three devices. 


\section{Material and Method}

This is a clinical proof-of-concept study performed in one neonatal center of the Stella Maris Hospital, using neonatal laminar flow unit, described below, neonatal intensive care incubator and radiant warmer. After approval by the ethics and research committee of the Stella Maris Hospital, and signing the informed consent by the patient's heads; we included infants born with gestational age between 38 weeks until 42 weeks gestational age and with body temperature less than or equal to $36,2^{\circ} \mathrm{C}$.Written informed consent was obtained from the parents by staff not involved in the study and the study was approved by the ethics committee of the Hospital. Descriptive statistics was used to compare a total of 71 newborns with neonatal conditions that required a restricted control of body temperature, 29 newborns in use of the neonatal intensive care incubators made in Brazil, 28 in use neonatal laminar flow unit made in Brazil and 14 newborns in use of the radiant warmer also made in Brazil.

The laminar flow incubator used in this study was developed in Sao Paulo, Brazil, by the International Neurodevelopment Neonatal Center (CINN) as a lower cost alternative to other technology. A detailed description of the unit and its operating characteristics has previously been published [5]. Briefly, it is an open unit with free access to the newborn infant, with significant advantages over a radiant warmer. It features a HEPA filter and laminar flow, and the unit meets the requirements of the International Standard Organization 4 standard of isolation. Temperature is controlled by convection, like an incubator, and $70 \%$ relative humidity is provided. The unit produces less noise than standard incubators and employs a lower magnetic field strength.

We made a table to compare, with a numeric score, the obtained results in the evaluation of the three equipment's.

We have evaluated these items:

1. The speed of recovery of body temperature of newborns in use of the three equipment

2. Bacteria contamination level in the microenvironment inside the three equipment
3. Humidity level in the microenvironment inside of the three equipment

4. Easy access to the care of the newborn in use of the three equipment

5. Level noise of the microenvironment in the three equipment

6. Spent time for terminal disinfection of the three devices

According to the result obtained we assign the value 0 to worse result, 1 to intermediate result and 2 to better result found in the evaluation of the three equipment. In case of similar results, we have attributed the similar punctuation; in the case of very disparate results, we have assigned the lowest possible score for the result shoot.

We have used for analysis a brand the intensive care incubator Vision 2186 made by the company Fanem, a brand radiant warmer Matrix by the company Olidef, and a prototype of the Laminar Flow Unit by the company Mendel Medical. The three companies from Brazil.

\section{Results}

The newborn's incubator group had a mean weight of 3000 grs \pm 220 grs, the newborn's radiant warmer's group had a mean weight of $3120 \mathrm{grs} \pm 110 \mathrm{grs}$, and finally newborn's laminar flow unit group had a mean weight of 3225 grs \pm 150 grs. Regarding gestational age, the newborn's incubator group had a mean gestational age of $39.7 \pm 5$ weeks, the newborn's radiant warmer's group had a mean gestational age of $40.1 \pm 4$ weeks, and finally newborn's laminar flow unit group had a mean gestational age of $40.3 \pm 7$ weeks. We didn't find significant differences between three groups about weight and gestational age.

With regard to item 1 , the speed of recovery of body temperature of newborns, the measure of temperature was made with skin sensor temperature) in the term newborns (between 38 until 42 weeks gestational age). In the Table 1 we have resulted the speed of recovery of body temperature of newborns in use of the three equipment.

Table 1:

\begin{tabular}{|c|c|c|c|c|}
\hline Groups & Newborns & Mean Initial Body Temperature & Mean Time Spent Recovering Body Temperature (>36.5 $\left.{ }^{\circ} \mathbf{c}\right)$ & Punctuation \\
\hline Incubator & 29 & $35.8^{\circ} \mathrm{C}$ & 5 Hours and 50' & 0 \\
\hline Laminar Flow Unit & 28 & $35.9^{\circ} \mathrm{C}$ & 2 Hours and 10' & 2 \\
\hline Radiant Warmer & 14 & $36.0^{\circ} \mathrm{C}$ & 2 Hours and 20' & 2 \\
\hline
\end{tabular}

The time spent to recovery body temperature of the newborns in the use incubators was significative larger than the body temperature of the newborns in use of radiant warmer and lamina flow groups. The punctuation was 0 to the worst result (incubator group), and 2 to the best result (radiant warmer and laminar flow groups). The results of the laminar flow and radiant warmer groups didn't have significative difference.
About item 2, Bacteria Contamination level of the microenvironment, we have measured particles size larger than 0.3 $\mu \mathrm{m}$ per cubic feet (compatible with the size of bacteria); we have used a particles analyzer brand Solair 3200 (Lighthouse Worldwide solutions-Netherlands). In the Table 2 we have the results this analysis and its respective punctuation 
Table 2:

\begin{tabular}{|c|c|c|}
\hline Groups & Particles Number & Punctuation \\
\hline Incubator & $60.000 /$ cubic feet & 1 \\
\hline Laminar Flow Unit & $600 /$ cubic feet & 2 \\
\hline Radiant Warmer & $200.000 /$ cubic feet & 0 \\
\hline
\end{tabular}

We have observed a indisputable greater capacity of isolation of the microenvironment in the Neonatal laminar flow unit, when compare to an incubator and radiant warmer. In relation to item 3 , air humidity in the microenvironment, we have used analyzer to measure air humidity and temperature brand arTesto606-2 (TestoNew Jersey-EUA). In the Table 3 we can observe the punctuation of each of the equipment.

Table 3:

\begin{tabular}{|c|c|c|}
\hline Groups & Humidity & Ponctuation \\
\hline Incubator & $85 \%$ & 2 \\
\hline Laminar Flow Unit & $70 \%$ & 1 \\
\hline Radiant Warmer & $20 \%$ & 0 \\
\hline
\end{tabular}

The incubator was able to supply the higher humidity concentration, when closed incubator, when compared to the laminar flow unit and radiant warmer had worse results because this equipment wasn't able to supply humidity.

In reference of item 4, we consulted 20 professionals (physician, nurses) that had opportunity to work with the three equipment (Table 4).

\section{Table 4:}

\begin{tabular}{|c|c|c|}
\hline GROUPS & EASE OF ACCESS & PUNCTUATION \\
\hline INCUBATOR & RESTRICTED & 0 \\
\hline LAMINAR FLOW UNIT & TOTAL & 2 \\
\hline RADIANT WARMER & TOTAL & 2 \\
\hline
\end{tabular}

In this item, we didn't found differences between radiant warmer and neonatal laminar flow unit, though there was a frequent complaint about the impact of temperature on the care staff. The incubator, undoubtedly, had the worse result.

With regard to item 5 , noise level of the microenvironment, we have utilized a digital decibelmeterbrand DEC-590(InstruthermBrazil) and we can observed the results in the Table 5 below.

\section{Table 5:}

\begin{tabular}{|c|c|c|}
\hline Groups & $\begin{array}{c}\text { Noise Level of the } \\
\text { Microenvironment (Decibels) }\end{array}$ & Punctuation \\
\hline Incubator & 50 & 0 \\
\hline Laminar Flow Unit & 50 & 0 \\
\hline Radiant Warmer & 10 & 2 \\
\hline
\end{tabular}

It's evident the advantage of the radiant warmer, in this question, since this equipment does not require the use of a motor, which is the biggest source of noise in the incubator and laminar flow unit.

Table 6:

\begin{tabular}{|c|c|c|}
\hline Groups & $\begin{array}{c}\text { Time Spent on Terminal } \\
\text { Disinfection }\end{array}$ & Punctuation \\
\hline Incubator & $50^{\prime}$ & 0 \\
\hline Laminar Flow Unit & $15^{\prime}$ & 2 \\
\hline Radiant Warmer & $15^{\prime}$ & 2 \\
\hline
\end{tabular}

Finally, in the Table 6, we can check the time spent on terminal disinfection of the three devices

In this item the difference in the work requirement of work for terminal disinfection is brutal in favor of the laminar flow unit and radiant warmer when compared to the incubator; which is reflected in the difference spent on terminal disinfection of this equipment. In the Table 7, below, we have the score with final punctuation of the three devices.

Table 7:

\begin{tabular}{|c|c|c|c|c|c|c|c|}
\hline & $\begin{array}{c}\text { Mean Time Spent } \\
\text { Recovering Body } \\
\text { Temperature }\left(>36.5^{\circ} \mathrm{c}\right)\end{array}$ & $\begin{array}{l}\text { Particles } \\
\text { Number }\end{array}$ & Humidity & Ease of Access & $\begin{array}{l}\text { Noise Level of the } \\
\text { Microenvironment }\end{array}$ & $\begin{array}{l}\text { Time Spent } \\
\text { on Terminal } \\
\text { Disinfection }\end{array}$ & Total \\
\hline Incubator & 0 & 1 & 2 & 0 & 0 & 0 & 3 \\
\hline Laminar Flow Unit & 2 & 2 & 1 & 2 & 0 & 2 & 9 \\
\hline Radiant Warmer & 2 & 0 & 0 & 2 & 2 & 2 & 8 \\
\hline
\end{tabular}

\section{Discussion}

The use of incubators in the treatment of newborns has come a long time, becoming a paradigm within modern neonatology; however, its limitations in practice are well known, which led to the search for other alternatives such as radiant warmer and recently laminar flow unit $[1,2,5]$.
The main intention of this study is to compare objective data of the three equipment, offering technical subsidies that help us in choosing a particular device according to the clinical situation faced. In the first analysis, it is evident the greater capacity of isolation of the laminar flow unit, if we associate it with its ability to deliver convective heat quickly with a servo control system and 
humidity and finally total access to manage newborns; is evident the advantages this equipment, in relation to the delivery room, in relation to the radiant warmer (radiant heat, without humidity and isolation).

With regard to the evaluation of equipment in neonatal intensive care and intermediate care, the advantage of the neonatal laminar flow unit over incubators and/or radiant warmer, in term newborns and instable premature newborns, that they need ease access with humidity and with low level contamination in the microenvironment. However, in stable premature babies, the intensive care incubators that it is able to supply higher humidity level, should be the equipment of choice. Other specific situations such as surgical procedures and transport of newborns require further study.

\section{Conclusion}

In this trial with objective evaluation data, we were able to demonstrate the advantages of the neonatal laminar flow unit in specific situations, such delivery room and term newborns and instable premature newborns care. Further studies are needed to establish further possibilities for the use of neonatal laminar flow unit.

\section{Conflict of Interest}

Jose Maria Rodriguez Perez is a holder of the Laminar Flow Unit patent.

\section{References}

1. Baker JP (2000) The incubator and the medical discovery of the premature infant. J Perinatol 20(5): 321-328.

2. Bell EF (1983) Infant incubators and radiant warmers. Early Hum Dev 8(3-4): 351-375.

3. Vecoflow (2015) Laudo de contaminação ambiental dos equipamentos Neonatflow, incubadora Vision e Berço de calor radiante Total Care.

4. Rodarte MDO, Scochi CGS, Leite AM, Fujinaga CL, Zamberlan NE (2005) 0 Ruído gerado durante a manipulação das incubadoras: implicações para o cuidado de enfermagem. Rev Latino Ame Enfermagem 13(1): 79-85.

5. Perez JMR, Golombek SG, Fajardo C, Sola A (2013) A laminar flow unit for the care of critically ill newborns infants. Med Devices 6: 163-167.

6. Perez JMR, Alpan G, Feldman A (2015) Treating Hypoxic Ischemic Encephalopathy with Hypothermia. Neoreviews 16(7):e413-e419.

7. Perez JMR, Golombek S, Alpan G, Sola A (2015) Using a novel laminar flow unit provided effective total body hypothermia for neonatal hypoxic encephalopathy. Acta Paediatr 104(11): e483-e488. 